\title{
O capitalismo enquanto cultura: crítica da racionalidade econômica
}

Capitalism as culture: critique of economic reason

Marcelo Soares Bandeira de Mello Filho(1)

(1) Universidade Federal de São João del-Rei

\section{Abstract}

The paper critically analyses how economic thought deals with the concept of culture. The first part of the text discusses how the dominant economic approaches, from Adam Smith to the neoclassical economics, explain the culture. According to these approaches, human rationality is predominantly utilitarian and calculating, the cultural sphere is external to the economic one and only indirectly influences it. The second part of the paper presents key elements for the understanding of culture in three fundamental heterodox economics thinkers, Marx, Veblen and Furtado. These authors deeply criticize the dominant economic thought and construct concepts that historicize and criticize capitalist societies. The third section presents criticisms on the way both orthodox and heterodox economic thoughts portray nonWestern cultures, assume the predominance of capitalist rationality in modern society and presuppose that economic rationality is non-cultural.

\section{Keywords}

economic anthropology, economic thought, culture.

JEL Codes A12, A13, Z13.

\section{Resumo}

Este artigo analisa criticamente como o pensamento economico trabalha o conceito de cultura. $\mathrm{Na}$ primeira parte do texto é discutido o tratamento da cultura pelas abordagens econômicas dominantes, desde Adam Smith até a economia neoclássica. De acordo com tais abordagens, a racionalidade humana é predominantemente calculista e utilitarista, e a esfera cultural é externa ao âmbito econômico e só o influencia indiretamente. A segunda parte do artigo apresenta elementos centrais para o entendimento da cultura em três autores fundamentais da heterodoxia econômica: Marx, Veblen e Furtado. Esses autores criticam profundamente o pensamento econômico dominante e constroem conceitos que historicizam e criticam as sociedades capitalistas. A terceira seção apresenta críticas sobre como os pensamentos econômicos ortodoxo e heterodoxo retratam culturas não ocidentais, assumem a predominância da racionalidade capitalista na sociedade moderna e pressupõem que a racionalidade econômica não é cultural.

\section{Palavras-chave}

antropologia econômica, pensamento econômico, cultura.

Códigos JEL A12, A13, Z13. 


\section{Introdução}

O presente artigo discute como as diversas teorias econômicas, tanto aquelas ligadas à ortodoxia quanto as abordagens heterodoxas, ${ }^{1}$ trabalham a ideia de cultura. Será observado que as diversas abordagens econômicas sobre o assunto tendem a reduzir os fenômenos culturais a aspectos secundários ou externos à vida econômica, que, por sua vez, é caracterizada como uma esfera onde imperaria um tipo específico de racionalidade, ligado a elementos técnicos e quantitativos da produção e do consumo.

$\mathrm{Na}$ primeira parte do texto, autores fundamentais do pensamento econômico dominante no século XIX, a economia política clássica, e no século XX, a abordagem neoclássica, são discutidos. Será observado que autores como Smith, Bentham, Jevons, Menger e a economia neoclássica da cultura procuram reduzir o comportamento econômico humano a elementos pretensamente naturais, quantificáveis ou completamente racionais e redutíveis às preferências individuais. Se gundo esse tipo de abordagem, a cultura é um aspecto secundário, exógeno à vida econômica, redutível a preferências individuais.

Na segunda parte do texto, são discutidas abordagens econômicas alternativas, que procuram analisar de forma crítica a modernidade capitalista. As teorias de Marx, Veblen e de Celso Furtado questionam as supostas naturalidade e racionalidade da economia capitalista. Entretanto, mesmo esses teóricos críticos da visão econômica convencional consideram que existem elementos estritamente ligados à técnica, à produção ou aos valores de uso, que escapariam ao âmbito cultural.

1 As definições de ortodoxia, heterodoxia e economia mainstream são imprecisas. De acordo com Dequech (2007), a ortodoxia pode ser definida como a escola de pensamento dominante num período histórico, enquanto a heterodoxia, que é de definição mais imprecisa, pode ser delimitada negativamente, em oposição à ortodoxia. Já a economia mainstream engloba autores e escolas de pensamento de prestígio nas principais instituições de ensino e pesquisa. A economia neoclássica, abordagem dominante na atualidade, se caracteriza por: 1) ênfase na maximização da utilidade como critério da racionalidade; 2) ênfase no equilíbrio; 3) a desconsideração pela incerteza no sentido forte (Dequech, 2007, p. 280).

Por sua vez, Lee (2009) argumenta que a economia ortodoxa adota uma série de proposições, tais como escassez, equilíbrio, racionalidade, preferências e individualismo metodológico. $\mathrm{O}$ autor identifica as abordagens heterodoxas como aquelas que rejeitam a totalidade (ou boa parte) desses princípios e procuram enfatizar o realismo, as estruturas sociais, a incerteza e a história. Ele inclui entre as mais relevantes abordagens heterodoxas a escola austríaca, a economia feminista, a abordagem institucional-evolucionária, a economia marxista-radical, a escola pós-keynesiana, a abordagem sraffiana e a economia social. Ainda segundo Lee (2008), diversos autores procuram integrar e realizar diálogos entre diversas das perspectivas citadas. 
$\mathrm{Na}$ terceira parte são discutidos pontos de vista da antropologia da economia (e da antropologia em geral) que analisam as relações econômicas e a modernidade capitalista como relações sociais inseridas na esfera da cultura, sendo, portanto, irredutíveis a aspectos meramente técnicos ou materiais. A própria concepção de que existem elementos unicamente técnicos ou materiais na vida social faz parte do ponto de vista cultural da modernidade capitalista. Autores como Malinowski, Mauss, Lévi-Strauss, Viveiros de Castro, Latour e Sahlins argumentam que o que chamamos de vida econômica se insere em aspectos culturais mais amplos, tanto na sociedade moderna quanto nas não modernas. Ademais, questionam a concepção da modernidade enquanto uma época de racionalidade e desencantamento e trazem elementos para o entendimento do capitalismo como um sistema econômico e cultural.

\section{A cultura do ponto de vista da economia política clássica e da economia neoclássica}

pensamento econômico dominante apresenta enorme dificuldade em trabalhar o conceito de cultura e tende, desde os tempos de Adam Smith, a negar a cultura, radicalizando a visão moderna ${ }^{2}$ segundo a qual as práticas e instituições da nossa sociedade são naturais, eternas ou derivadas estritamente de uma lógica pura. Desse modo, as relações de casamento, propriedade, alimentação (entre muitas outras) dos povos nativos, da antiguidade clássica greco-romana, da Europa medieval e das sociedades não modernas como um todo são consideradas partes de culturas arcaicas, desaparecidas ou em via de desaparecimento, enquanto as instituições modernas de casamento, propriedade, alimentação são vistas como racionais. $\bigcirc$ mesmo acontece com as relações econômicas que, segundo o pensamento ortodoxo, não seriam parte de uma vida social e cultural mais ampla, mas antes resultado da natureza ou da racionalidade humanas.

Adam Smith, considerado um dos principais fundadores do pensamento econômico, explica, na obra Investigação sobre a natureza e as causas da riqueza das nações, as relações econômicas capitalistas a partir do lento desenvolvimento de uma propensão pretensamente natural a "intercam-

2 O conceito de modernidade é apresentado na terceira parte do artigo. 
biar, permutar ou trocar". A partir dessa tendência natural seria derivada a divisão do trabalho, causa de aumento da produtividade e da própria riqueza das nações.

Essa divisão do trabalho, da qual derivam tantas vantagens, não é, em sua origem, o efeito de uma sabedoria humana qualquer, que preveria e visaria esta riqueza geral à qual dá origem. Ela é a consequência necessária, embora muito lenta e gradual, de uma certa tendência ou propensão existente na natureza humana que não tem em vista essa utilidade extensa, ou seja: a propensão a intercambiar, permutar ou trocar uma coisa pela outra (Smith, 1776, p. 65).

Contemporaneamente à obra de Smith, outro importante autor procurava bases fundar as para o entendimento do comportamento humano, mas a partir de um ponto de vista diverso ao do filósofo escocês. Jeremy Bentham procurava explicar e aprimorar as leis, a vida política, a filosofia e a vida econômica a partir do conceito de utilidade, que seria capaz de explicar a ação humana.

O termo utilidade designa aquela propriedade existente em qualquer coisa, propriedade em virtude da qual o objeto tende a produzir ou proporcionar benefício, vantagem, prazer, bem ou felicidade (tudo isso, no caso presente se reduz à mesma coisa) ou (o que novamente equivale à mesma coisa) a impedir que aconteça o dano, a dor, o mal ou a infelicidade para a parte cujo interesse está em pauta (Bentham, 1780, p. 4).

A partir da utilidade, Bentham procurou construir uma ciência do bem-estar, com a exatidão numérica da física. Essa nova ciência humana poderia ser utilizada para calcular a utilidade com base em intensidade, duração, pureza, certeza ou incerteza, do prazer e da dor. Seria possível calcular a utilidade presente em cada ação humana e, a partir daí, derivar as melhores instituições para o funcionamento da sociedade.

A natureza colocou o gênero humano sob o dominio de dois senhores soberanos: a dor e o prazer. Somente a eles compete apontar o que devemos fazer, bem como determinar o que na realidade faremos [...]. Os dois senhores de que falamos nos governam em tudo o que fazemos, em tudo o que dizemos, em tudo o que pensamos, sendo que qualquer tentativa que façamos para sacudir este senhorio outra coisa não faz senão demonstrá-lo e confirmá-lo (Bentham, 1780, p. 3).

A filosofia social utilitarista foi um segmento relativamente secundário do pensamento econômico durante as primeiras décadas do século XIX, embora sempre tenha estado presente em autores da França, da Inglaterra e da Alemanha. Uma célebre dificuldade do utilitarismo era o chamado "paradoxo da água e do diamante". Os utilitaristas não conseguiam explicar por que a água é muito útil e barata enquanto o diamante é pouco útil e caro. A resposta utilitarista a esse enigma deu origem ao marginalismo 
na economia, que enfatiza as diferenças marginais de utilidade em vez da utilidade total.

Nos primeiros anos da década de 1870, Jevons, Menger e Walras, respectivamente na Inglaterra, na Áustria e na França, aprofundaram o desenvolvimento do marginalismo na economia. O marginalismo, que viria a se tornar a base da economia neoclássica, corrente dominante na economia do século XX, considera que o comportamento econômico é derivado de escolhas otimizadoras dos indivíduos. Não seriam, portanto, fatores históricos, sociais e culturais que explicariam a vida socioeconômica, mas sim as escolhas racionais dos indivíduos, a partir de cálculos de prazer e sofrimento, ou perdas e ganhos.

O pensamento econômico, dessa forma, se afasta das demais ciências humanas, e procura se espelhar na matemática e na física newtoniana. Desse modo, segundo Menger: "os fenômenos da vida econômica se regem estritamente por leis iguais às leis da Natureza" (MENGER, 1871, p. 240). Aprofundando a comparação entre a vida econômica e a natureza, Jevons argumenta que a teoria econômica deveria ser construída de forma análoga à mecânica. ${ }^{3} \mathrm{O}$ comportamento dos agentes econômicos seria semelhante ao funcionamento de uma alavanca.

A Teoria da Economia, tratada dessa forma, sugere uma estreita analogia com a ciência da Mecânica Estática, e verifica-se que as Leis de Troca se assemetham às Leis do Equilibrio de uma alavanca, determinadas sob o princípio das velocidades virtuais. A natureza da Riqueza e do Valor explica-se por meio da consideração de minúsculas quantidades de prazer e sofrimento, assim como a Teoria da Estática é feita de forma a sustentar-se na igualdade de indefinidamente pequenas quantidades de energia (Jevons, 1871, p. 16).

Nas últimas décadas do século XIX e nas primeiras do século XX, diversas teorias foram desenvolvidas tentando explicar fenômenos como o comportamento dos consumidores e das firmas, o crescimento econômico e a distribuição de renda, a partir dos princípios da escolha otimizadora individual, embora a pretensão de obter cálculos de quantidades de utilidade tenha sido abandonada.

Lionel Robbins, em ensaio de 1932, fez a descrição da ciência econômica que se tornou a definição mais difundida pela economia ortodoxa: "a ciência que estuda o comportamento humano como uma relação entre fins e meios escassos, que têm usos alternativos" (Robbins, 1932, p. 15). 3 Ao longo do século XIX, o pensamento econômico procurou criar uma ciência social inspirada na física (Mirowski, 1989). 
Em resumo, a economia seria a ciência que estuda as escolhas individuais frente a recursos escassos. Essa escolha seria realizada por todo e qualquer indivíduo racional, seja qual for a cultura na qual esteja inserido.

A economia neoclássica se complexificou ao longo do século XX, especialmente graças aos avanços da computação (Mirowski, 2002), e ampliou a utilização do arcabouço teórico do indivíduo maximizador racional para a explicação dos mais diversos fenômenos sociais, entre os quais a formação de casais, a discriminação racial e mesmo os vícios por álcool, drogas e trabalho (Becker, 1957; Becker; Murphy, 1988).

Até recentemente a economia neoclássica negligenciou o tema da cultura. Quando se debruçam sobre o assunto, economistas neoclássicos consideram que as diferenças individuais e coletivas de gosto são explicadas por fatores culturais. Analisam evidências empíricas acerca da relação entre diferenças culturais e os resultados econômicos alcançados por famílias ou países (Fernández, 2008; Guiso; Sapienza; Zingales, 2006). Reconhecem que aspectos culturais são fundamentais para a determinação das instituições prevalecentes nas diferentes nações contemporâneas e que as instituições, por sua vez, ajudam a explicar os padrões atuais de crescimento e de desenvolvimento (Grief, 1994; Fernández, 2008).

A economia neoclássica da cultura procura explicar diferenças de performance econômica estudando como "os agentes, com dadas crenças e preferências, reagem a mudanças no ambiente político, nas instituições e na tecnologia" (Fernández, 2008). Além dos impactos que as preferências exercem sobre os indivíduos, elas impactam a maneira como "as sociedades alocam recursos escassos". Por um lado, no plano individual, as crenças e preferências determinam aspectos cruciais da vida individual, tais como a participação de uma determinada mulher no "mercado de trabalho formal" ou o grau em que o "racismo é tolerado". Por outro lado, no nível coletivo, as crenças e preferências ajudam a determinar, por exemplo, o tamanho do "Estado de bem-estar social", a "legalidade da escravidão" ou a "parcela do orçamento direcionada à ajuda internacional” (Fernández, 2008).

Ainda de acordo com essa abordagem, a cultura é definida como um conjunto de "crenças costumeiras e valores" partilhado por grupos "étnicos, religiosos ou sociais" de uma geração para outra (Guiso, Sapienza, Zingales, 2006, p. 23). Segundo Fernández (2008), a "maneira mais comum de pensar o papel da cultura na economia" é a de definir a cultura como um conjunto de "diferenças sistemáticas (entre grupos) em termos de pre- 
ferências e crenças". Desse modo, não seria necessário modificar "o modelo econômico padrão" para incorporar questões relativas ao mundo da cultura, já que as distintas culturas podem ser reduzidas a diferenças em termos de preferência que, por sua vez, resultam na "escolha de estratégias de equilíbrio em um jogo com equilíbrios múltiplos e preferências padronizadas" (Fernández, 2008). Os economistas neoclássicos podem tratar as questões relativas à cultura "mantendo o pressuposto econômico padrão" de que cada indivíduo maximiza sua utilidade (Guiso, Sapienza, Zingales, 2006, p. 23). Além de modelos baseados na otimização das escolhas racionais, outras das técnicas de pesquisa utilizadas por essa abordagem são a análise histórica comparativa, a econometria e a teoria dos jogos (Grief, 1994; Fernández, 2008).

Segundo o pensamento econômico dominante - seja a economia política clássica dos séculos XVIII e XIX, seja a economia neoclássica do final do século XIX e do século XX -, a cultura é representada por crenças, preferências e tradições externas ao âmbito econômico. Nessa esfera, os agentes seriam guiados pela racionalidade, por escolhas individuais em termos de perdas e ganhos, custos e benefícios. Essa suposta racionalidade não é explicada, não é considerada parte da cultura. Caso realmente os agentes raciocinem em termos de custos e benefícios, perdas e ganhos, esse mesmo tipo de pensamento não é considerado culturalmente específico, pois é visto como a racionalidade humana por excelência. Outras maneiras de ver o mundo é que seriam equivocadas e levariam a resultados econômicos subótimos.

\section{A cultura segundo a economia heterodoxa}

Esta seção apresenta elementos para a discussão da cultura nas obras de Marx, de Veblen e de Furtado. A escolha desses autores se deveu ao fato de os dois primeiros serem os principais representantes de duas das mais importantes abordagens heterodoxas em economia, o marxismo e o institucionalismo. Já a escolha de Celso Furtado foi motivada pela ênfase que o autor dá à cultura como elemento determinante dos processos de desenvolvimento e subdesenvolvimento. Ademais, Furtado é autor de destacada contribuição para o entendimento do processo histórico de formação e de desenvolvimento da economia brasileira. 
Marx foi o principal autor que questionou a maneira como a economia política clássica procurava entender a sociedade moderna. Na famosa passagem de $O$ capital na qual investiga o "fetichismo ${ }^{4}$ da mercadoria", o autor questiona a naturalização da economia capitalista presente no pensamento econômico da época, que, nas décadas seguintes à morte de Marx, seria ampliada pela economia neoclássica. Autores como Smith, Ricardo, assim como a economia neoclássica contemporânea, realizariam "Robinsonadas" imaginando que todas as pessoas se comportam como o personagem literário Robinson Crusoé, que realizava cálculos de custo e benefício na ilha deserta em que ficou após o navio em que viajava naufragar.

De acordo com Marx, as relações sociais capitalistas aparecem, na análise convencional da economia, como eternas, naturais. Esse é o caráter fetichista da mercadoria, o fato de as relações sociais construídas ao longo da história parecerem inerentes a todas as sociedades humanas. Fazendo uma analogia com o mundo da religião, o autor argumenta que a forma mercadoria parece, para a economia política clássica da época, com as divindades do mundo religioso: eternas e anteriores às formas sociais, em vez de se evidenciarem como o que realmente são: formas historicamente construídas.

$E$ apenas uma relação social determinada entre os próprios homens que aqui
assume, para eles, a forma fantasmagórica de uma relação entre coisas. Desse
modo, para encontrarmos uma analogia, temos de nos refugiar na região nebu-
losa do mundo religioso. Aqui, os produtos do cérebro humano parecem dotados
de vida própria, como figuras independentes que travam relação umas com as
outras e com os homens [...]. A isso eu chamo de fetichismo, que se cola aos pro-
dutos do trabalho tão logo eles são produzidos como mercadorias e que, por isso,
é inseparável da produção de mercadorias (Marx, 1867, p. 148).

Esse fetichismo da mercadoria decorre da própria forma-mercadoria, ou seja, da maneira como o trabalho social é organizado e distribuído nas sociedades capitalistas. Por causa do fetichismo, os produtos do trabalho humano aparentam possuir valores e preços assim como possuem características físicas, tais como peso, altura e volume. A compra e venda de produtos nos mercados obscurece o fato de que trabalhadores estão se relacionando com outros trabalhadores dispersos ao redor do mundo. Essa relação social é ocultada e aparece como mera relação entre objetos, a troca de dinheiro por mercadoria.

4 A opção por avaliar a visão marxiana da cultura a partir do fetichismo se deve à capacidade dessa categoria ser utilizada para criticar as concepções de cultura da economia política clássica e da economia neoclássica e de revelar o caráter histórico e, portanto, culturalmente específico, das relações sociais capitalistas. 
O caráter misterioso da forma-mercadoria consiste, portanto, simplesmente no fato de que ela reflete aos homens os caracteres sociais de seu próprio trabalho como caracteres objetivos dos próprios produtos do trabalho, como propriedades sociais que são naturais a essas coisas e, por isso, reflete também a relação social dos produtores com o trabalho total como uma relação social entre os objetos, existente à margem dos produtores (Marx, 1867, p. 147).

Como visto, as relações sociais capitalistas, provocando essa fetichização da forma mercadoria, fazem com que "relações diretamente sociais" entre pessoas apareçam como "relações sociais entre coisas". Entretanto, isso não é tudo. A forma mercadoria também implica em "relações reificadas entre pessoas" (Marx, 1867, p. 148). Os trabalhadores e os consumidores podem aparecer, do ponto de vista do capital, como meros mecanismos do sistema de produção e consumo. Reificados, os trabalhadores muitas vezes têm sua dimensão humana rebaixada pela lógica da produção capitalista, sendo reduzidos a custos de produção. Marx apresenta, ao longo de todo o livro I de $O$ capital, inúmeros exemplos de péssimas condições de trabalho existentes na Inglaterra do século XIX. Tais condições não estão ausentes no capitalismo contemporâneo.

Marx, em suas pesquisas, desenvolve uma análise profunda e crítica da sociedade da sua época. Entretanto, assume algumas características da cultura da sua época como universais. Considera o raciocínio político em termos de consciência e de interesse de classe como a forma básica de racionalidade dos grupos sociais, ${ }^{5}$ ponto que será criticado à frente. Marx dá um importante passo ao relativizar e contextualizar historicamente a forma mercadoria. Entretanto, é ambíguo no que se refere ao mundo natural. Por um lado, é pioneiro na crítica do capitalismo enquanto um sistema econômico irracional, voltado para a produção pela produção e para o consumo pelo consumo. Sua obra possui importantes críticas à destruição ambiental. ${ }^{6}$ Por outro lado, assume, implicitamente, a visão antropocêntrica, segundo a qual o mundo natural seria apenas fonte de valor de uso

5 "A história de todas as sociedades até hoje existentes é a história das lutas de classes" (Marx, Engels, 1848, p. 39).

6 "E todo progresso da agricultura capitalista é um progresso na arte de saquear não só o trabalhador, mas também o solo, pois cada progresso alcançado no aumento da fertilidade do solo por certo período é ao mesmo tempo um progresso no esgotamento das fontes duradouras dessa fertilidade. Quanto mais um país, como os Estados Unidos da América do Norte, tem na grande indústria o ponto de partida de seu desenvolvimento, tanto mais rápido se mostra esse processo de destruição. Por isso, a produção capitalista só desenvolve a técnica e a combinação do processo de produção social na medida em que solapa os mananciais de toda a riqueza: a terra e o trabalhador" (Marx, 1867, p. 573-574). 
para os seres humanos. ${ }^{7}$ Será observado, a seguir, que o antropocentrismo é típico da modernidade capitalista e não era (ou não é) um aspecto típico de várias culturas tradicionais.

Além disso, em passagens pontuais, mas muito influentes, de sua obra, Marx subestima o papel da cultura, do direito e mesmo da política, ao considerá-las parte da superestrutura da sociedade, epifenômenos derivados da vida material (a infraestrutura da sociedade). Embora essa visão determinista e reducionista da cultura ${ }^{8}$ não seja a única interpretação possível da famosa passagem de Marx da Contribuição à crítica da economia política, ela marcou os trabalhos marxistas sobre a cultura por muito tempo?.

O resultado geral a que cheguei e que, uma vez obtido, serviu-me de guia para meus estudos, pode ser formulado, resumidamente, assim: na produção social da própria existência, os homens entram em relações determinadas, necessárias, independentes de sua vontade; essas relações de produção correspondem a um grau determinado de desenvolvimento de suas forças produtivas materiais. A totalidade dessas relações de produção constitui a estrutura econômica da sociedade, a base real sobre a qual se eleva uma superestrutura jurídica e política è à qual correspondem formas sociais determinadas de consciência. O modo de produção da vida material condiciona o processo de vida social, política e intelectual. Não é a consciência dos homens que determina o seu ser; ao contrário, é o seu ser social que determina sua consciência (Marx, 1859, p. 47).

O segundo autor comentado nesta seção é Thorstein Veblen, considerado o fundador do institucionalismo original, movimento teórico predominantemente estadunidense, que apenas parcialmente incorporou o legado de seu fundador. Veblen foi influenciado pela escola histórica alemã, pela economia política clássica, pelo pensamento de Darwin, pelo marxismo e pelos trabalhos de antropólogos, etnólogos e historiadores.

Sem dúvida, a referência mais idiossincrática de Veblen é a teoria evolucionária. Com base em uma leitura bastante particular do darwinismo, não incorrendo em diversos equívocos comuns na sua época, tais como o etnocentrismo e o reducionismo biológico, ele realizou uma profunda crítica

7 "O materialismo histórico, ao tratar a produção como um processo natural-pragmático de satisfação de necessidades, corre o risco de uma aliança com a economia burguesa no trabalho de aumentar a alienação de pessoas e coisas para um poder cognitivo maior" (Sahlins, 1976, p. 163).

$8 \mathrm{Na}$ introdução aos Grundrisse, Marx abandona qualquer determinismo e tece comentários que reconhecem, de maneira sofisticada, a "relação desigual do desenvolvimento da produção material com, por exemplo, o desenvolvimento artístico" (Marx, 1857-1858, p. 62), tomando como exemplos a cultura grega antiga e Shakespeare.

9 Ao longo do século XX, diversos autores inspirados pela obra de Marx, tais como Gramsci, Lukács, Adorno e Benjamin procuraram sofisticar a concepção marxista acerca da cultura. Pelo fato de não terem feito obras de teoria econômica, mas não serão analisados neste artigo. 
ao pensamento econômico clássico, à escola histórica, à escola austríaca e ao marginalismo no seu famoso artigo de 1898, Why is economics not an evolutionary science?. Nesse texto, Veblen defende que a economia deveria se tornar uma ciência evolucionária, assim como já seriam as ciências naturais e algumas ciências humanas, especialmente a antropologia, a etnologia e a psicologia. E assim define uma ciência evolucionária: "Oual quer ciência evolucionária [...] é um corpo teórico bem fechado. É a teoria de um processo, de uma sequência de eventos" (Veblen, 1898, p. 2).

Veblen define seu programa de pesquisa como a busca pela "gênese das instituições", ou seja, pelo surgimento e transformações "cumulativas" dos hábitos e convenções, enquanto "condicionados pelo ambiente material", pelas "mudanças culturais" e pelas características "inatas da espécie humana", os instintos, que "permanecem os mesmos" (Veblen, 1914, p. 2; 9).

A diferença entre os teóricos evolucionários e os teóricos tradicionais da economia seria que, enquanto os primeiros se ocupam apenas da "causação cumulativa desapaixonada", os últimos raciocinam em termos de "leis naturais", descrevem o que é normal, o que é natural, o equilíbrio e as causas dos distúrbios a essa normalidade (Veblen, 1898, p. 3-7). Cabe destacar que, como indica Veblen, o processo de evolução social é um processo não teleológico, sem um "fim predeterminado". Nesse sentido, Veblen (1906; 1907) critica a visão de Marx e Engels acerca da importância da luta de classes como um processo consciente e baseado em interesses materiais. Argumenta que esse raciocínio não é nem darwinista nem hegeliano, mas inspirado nas doutrinas "liberais-utilitaristas" da economia, que seriam de origem inglesa. Além disso, Marx e Engels teriam adotado uma concepção teleológica ${ }^{10}$ da história, em vez de analisá-la do ponto de vista da "causação cumulativa cega" evolucionária, que é "essencialmente mecânica" (Veblen, 1907, p. 302-304).

Veblen define as instituições como "hábitos mentais prevalecentes". São propensões dominantes em determinada época de uma sociedade. Um conjunto de instituições forma um esquema de vida, que pode ser compreendido como um tipo de mentalidade prevalecente em determinada "fase cultural" (Veblen, 1899, p. 88). Tanto o conceito de instituição quanto o de hábito mental trazem em seu bojo a síntese entre teoria e prática, rompendo, portanto, o dualismo que ocorre entre visões idealistas, de um

10 As polêmicas críticas de Veblen direcionadas a Marx não serão comentadas neste artigo. 
lado, e materialistas, de outro. Isso ocorre porque essas duas expressões indicam, simultaneamente, tanto uma forma corriqueira de pensar quanto uma forma corriqueira de agir.

Apesar de construir uma teoria da evolução institucional na qual o próprio metabolismo social é responsável pelas transformações do tecido institucional sem um fim predeterminado, equivocadamente, Veblen (1899, p. 13) acreditava que havia uma evolução cultural linear, em que uma fase cultural "pacífica" seria substituída por uma etapa "predatória", da qual a cultura moderna teria herdado diversas instituições arcaicas. Ademais, o autor argumentou que a simples utilização habitual das máquinas imprimiria aos hábitos de pensamento o raciocínio em termos de sequência causal, trazendo consequências sérias para as instituições pecuniárias. Os hábitos trazidos pela disciplina da máquina substituiriam formas mais arcaicas de compreensão do mundo, fundadas na crença "animística", no "direito de sangue", no "direito natural", no "nacionalismo" etc. Segundo o autor, a "disciplina do processo da máquina" reforça a "padronização da conduta e do conhecimento em termos de precisão quantitativa" e estimula um "hábito de apreender e explicar os fatos" em termos de "causa e efeito material" (Veblen, 1904, p. 66-67).

O último autor abordado nesta seção, Celso Furtado, foi um dos mais notáveis pensadores dos fenômenos do desenvolvimento e do subdesenvolvimento e se destacou como um dos principais economistas que enfatizaram a centralidade da cultura. Analisou, de forma crítica, a dependência dos países subdesenvolvidos em relação aos comportamentos culturais das nações centrais. A periferia do sistema econômico mimetizaria a cultura consumista do centro.

Essas reflexões me levaram à conviç̧ão de que a permanência do subdesenvolvimento se deve à ação de fatores de natureza cultural. A adoção pelas classes dominantes dos padrões de consumo dos países de níveis de acumulação muito superiores aos nossos explica a elevada concentração de renda, a persistência da heterogeneidade social e a forma de inserção no comércio internacional (Furtado, 1998, p. 60).

Furtado elaborou uma teoria do subdesenvolvimento em que o fenômeno é explicado a partir da difusão de técnicas mais produtivas originárias do centro do capitalismo mundial para as regiões periféricas. Denunciando o "falso neutralismo das técnicas" (Furtado, 1998, p. 47), o autor argumenta que os aumentos de produtividade estão associados, nas "economias cêntricas", nas quais haveria escassez de trabalho, às pressões sociais no 
sentido da melhoria das condições de vida, enquanto as mesmas técnicas, aplicadas na periferia do sistema econômico, promoveriam desemprego e concentração de renda.

O autor observa que o "sistema econômico" tende a ampliar a escala da acumulação e a "mundializar-se", destruindo total ou parcialmente as "formas senhorial, corporativa e artesanal de organização da produção" (Furtado, 1998, p. 61). Entretanto, esse processo não está imune a graves contradições. Desde os anos 1970, se acumulariam evidências de que a civilização iniciada pela revolução industrial aponta para um colapso. A pressão crescente sobre os "recursos não renováveis", sobre o "mundo físico" e a "poluição do meio ambiente" indicam que o desenvolvimento econômico, entendido como a ampliação do consumo que faça os países pobres desfrutarem as "formas de vida dos países ricos", é um "simples mito" (Furtado, 1974, p. 11-13, p. 88-89; 1998, p. 63-64).

Desse modo, Furtado conclui que é necessário "ampliar o campo do que é imediatamente possível", usar a "criatividade cultural" para construir novas formas sociais (FURTADO, 1978). Destaca que o desafio da atualidade é o de "mudar o curso da civilização" substituindo a "lógica da acumulação" pela lógica do "bem-estar social", pelo "exercício da liberdade" e pela "cooperação entre os povos" (Furtado, 1998, p. 64).

Marx, Veblen e Furtado construíram abordagens críticas extremamente sofisticadas sobre as economias capitalistas. Entretanto, ainda mantêm intocados alguns pressupostos do pensamento moderno no qual estão inseridos. Acreditam que existe uma dualidade entre natureza e sociedade. Não compreendem a sociedade como inerentemente imersa e imbrincada pela natureza. Os autores também observam na modernidade tendências de racionalização e ampliação da cientificidade na vida social, que estariam associadas ao avanço das forças materiais, à disciplina das máquinas e ao desenvolvimento de novas técnicas produtivas. Tanto os autores ortodoxos da economia quanto os heterodoxos acreditam que as formas tradicionais de produção e reprodução da vida e as culturas tradicionais a elas ligadas tendem a desaparecer com o desenvolvimento e a mundialização das relações sociais capitalistas. Críticas às visões presentes no pensamento econômico sobre a relação entre economia e cultura, assim como sobre a relação entre cultura e natureza, serão aprofundadas a seguir. 


\section{Visão antropológica: o capitalismo enquanto cultura}

A abordagem da sociologia e da antropologia acerca da cultura possibilita três níveis distintos de crítica sobre as visões de cultura e racionalidade prevalecentes no pensamento econômico. $O$ primeiro tipo de crítica se refere à maneira como a economia analisa a racionalidade de outras culturas, projetando visões utilitaristas, calculistas ou baseadas no interesse de classe em diversos povos. Um segundo nível de crítica rejeita que a racionalidade presente na sociedade ocidental moderna seja, de fato, utilitarista, calculista ou centrada em qualquer tipo de racionalidade econômica. Por fim, o terceiro tipo de crítica é o questionamento de que o utilitarismo, o calculismo e outras formas de racionalidade econômica sejam formas neutras, puras, sejam a racionalidade por excelência, externa ao âmbito da cultura.

Do ponto de vista da racionalidade presente nas outras sociedades, vários autores estudaram as relações de produção e de troca dos povos nativos, ramo das ciências humanas que ficou conhecido como antropologia econômica. Franz Boas, Bronislaw Malinowiski, Marcel Mauss, Karl Polanyi, entre outros, observaram que a circulação de objetos, animais e pessoas nos povos considerados "selvagens" em nada se reduz à troca mercantil predominante (mas não exclusiva) na modernidade capitalista.

\footnotetext{
Nas economias e nos direitos que precederam os nossos, nunca se constatam, por assim dizer, simples trocas de bens, de riquezas e de produtos num mercado estabelecido entre os indivíduos. Em primeiro lugar, não são indivíduos, são coletividades que se obrigam mutuamente, trocam e contratam; as pessoas presentes ao contrato são pessoas morais: clãs, tribos, famílias. [...] Ademais, o que eles trocam não são exclusivamente bens e riquezas, bens móveis e imóveis, coisas úteis economicamente. São, antes de tudo, amabilidades, banquetes, ritos, serviços militares, mulheres, crianças, danças, festas, feiras, dos quais o mercado é apenas um dos momentos, e nos quais a circulação de riquezas não passa de um dos termos de um contrato bem mais geral e bem mais permanente (Mauss, 1922, p. 190).
}

Presentes, dádivas e doações são considerados por Mauss "fenômenos sociais totais". São práticas simultaneamente religiosas, econômicas, jurídicas e morais. Nos "sistemas das prestações totais", a doação de presentes e a reciprocidade, no fundo, são rigorosamente obrigatórias, sob risco de guerra privada ou pública.

Malinowski estudou a circulação cerimonial (kula) de amuletos (vaygu'a) entre os povos ilhéus trobiandeses e publicou diversos estudos sobre esses povos, incluindo o livro Argonautas do Pacífico ocidental, de 1922. O kula é um circuito complexo de oferendas que se estende por ilhas distantes centenas 
de quilômetros. Os objetos doados nesse processo dificilmente podem ser utilizados no cotidiano. A importância deles é muito mais ritual e espiritual. A passagem a seguir ilustra a cosmovisão dos povos nativos do Pacífico. Segundo esse ponto de vista, o mundo é povoado por espíritos bons e ruins, que interagem com as pessoas. Os espíritos podem assumir a forma de espécies de animais. Os amuletos trocados nos circuitos kula são objetos mágicos, de adoração, capazes de confortar os espíritos que visitam as aldeias.

Assim, quando um espírito maligno, tauva'u, é encontrado numa aldeia ou perto dela na forma de uma cobra ou de um caranguejo terrestre, um vaygu'a é posto diante dele cerimonialmente, e isso é feito menos para subornar o espírito sacrificialmente com um presente que para exercer uma ação direta sobre sua mente e para torná-lo benévolo (Malinowski, 1922, p. 590).

De acordo com o autor, a circulação de amuletos dos povos tradicionais do Pacífico não pode ser reduzida à visão preconcebida de troca de mercadorias presente em nossa sociedade. Economistas e sociólogos que tentam explicar o kula a partir de princípios racionais e utilitaristas da sociedade ocidental se mostram incapazes de compreender a natureza complexa - simultaneamente econômica, mágica, estética, política e familiar - do fenômeno.

Em um ou dois lugares, nos capitulos anteriores, fez-se uma digressão um tanto detalhada para criticar a visão sobre a natureza econômica do homem primitivo tal como ela sobrevive em nossos hábitos mentais, bem como em alguns livros-texto - a concepção de um ser racional que não quer nada além de satisfazer suas necessidades simples, e o faz de acordo com o princípio econômico do menor esforço. Esse homem econômico sempre sabe exatamente onde estão seus interesses materiais e se move em direção a eles em linha reta. Na base da chamada concepção materialista da história encontra-se a ideia um tanto análoga de um ser humano que, em tudo o que arquiteta e persegue, não deseja outra coisa além de vantagem material de um tipo puramente utilitário. Ora, espero que, seja qual for o significado que o kula tenha para a etnologia, para a ciência geral da cultura, ele será útil para dissipar essas cruas concepções racionalistas da humanidade primitiva e induzir tanto o especulador quanto o observador a aprofundar a análise dos fatos econômicos (Malinowski, 1922, p. 592).

A visão de mundo que Malinowski e Mauss identificam em povos do $\mathrm{Pa}$ cífico e da América do Norte é a regra entre os povos nativos ao redor do mundo (Polanyi, 1944). Essas culturas consideram que o mundo que chamamos de natural é habitado por espíritos e pela magia. Em outras palavras, é um mundo encantado. A etnografia ameríndia identifica esse animismo, ou encantamento do mundo, presente em diversas culturas dos dias atuais. Por contraste, a cultura ocidental moderna procura desencantar o mundo, reduzir tudo aquilo que não se identifica com os humanos modernos a coisas e animais e reduzir os animais a coisas (Viveiros de Castro, 2018, p. 42-43). 
De acordo com Viveiros de Castro (2018, p. 42-43), a etnografia da América indígena contém uma miríade de referências a uma "teoria cosmopolítica" que entende o universo como povoado por "agentes subjetivos" ou "almas" que seriam bastante semelhantes ou até mesmo idênticas às almas que as pessoas teriam. Diversas entidades - "os deuses, os animais, os mortos, as plantas, os fenômenos meteorológicos, muitas vezes também os objetos e os artefatos" - teriam uma "alma semelhante".

Em célebre passagem, Lévi-Strauss comenta sobre as impressões iniciais de europeus e de ameríndios após a chegada dos primeiros às Américas. Enquanto os europeus questionam se os nativos possuíam alma, os indígenas afundavam corpos de espanhóis nos rios para investigar se os espíritos que eles achavam estar vendo tinham também um corpo orgânico comum. Nas palavras do autor:

Nas grandes Antilhas, alguns anos após a descoberta da América, enquanto os espanhóis enviavam comissões de investigação para pesquisar se os indigenas tinham ou não uma alma, estes últimos dedicavam-se a imergir brancos prisioneiros, a fim de verificar, após uma vigília prolongada, se seu cadáver estava ou não sujeito à putrefação (Lévi-Strauss, 1952, p. 334).

São notórias as diferenças culturais e sociais entre povos tradicionais e a sociedade moderna, muitas vezes chamada pelos povos nativos de "povo branco". De acordo com o relato do xamã yanomami Davi Kopenawa, organizado pelo antropólogo Bruce Albert, "os brancos" são preocupados com a acumulação de objetos, mercadorias e dinheiro. Destroem outras sociedades, matam a si mesmos, destroem o meio ambiente devido a esse imperativo de acumulação, mesmo que tal imperativo possa implicar a destruição do planeta em que vivemos.

Mas os brancos são gente diferente de nós. Devem se achar muito espertos por-
que sabem fabricar multidões de coisas sem parar [...]. Agora eles têm muitas
e muitas máquinas e fábricas. Mas nem isso é o bastante para eles. Seu pen-
samento está concentrado em seus objetos o tempo todo. Não param de fabricar
e sempre querem coisas novas. E assim, não devem ser tão inteligentes quanto
pensam que são. Temo que sua excitação pela mercadoria não tenha fim e eles
acabem enredados nela até o caos. Já começaram há tempos a matar uns aos
outros por dinheiro, em suas cidades, e a brigar por minérios ou petróleo que
arrancam do chão. Também não parecem preocupados por nos matar a todos
com as fumaças de epidemia que saem de tudo isso. Não pensam que assim
estão estragando a terra e o céu e que nunca vão poder recriar outros (Kopenawa;
Albert, 2015, p. 418-419).

De acordo com as visões presentes em boa parte das teorias econômicas, sejam essas de natureza ortodoxa ou heterodoxa, os seres humanos são movidos por princípios racionais, sejam eles de característica utilitarista, 
sejam eles baseados em interesses de classes ou outros grupos sociais. $\bigcirc$ segundo nível de crítica que a sociologia e a antropologia trazem para a análise da mentalidade econômica questiona a predominância da racionalidade econômica na modernidade. A esse respeito, o filósofo francês Bruno Latour (1994) considera que "jamais fomos modernos". Criticando as visões convencionais acerca da modernidade, argumenta que: "Em suas mãos o ocidental se torna um mutante, desenraizado, aculturado, americanizado, racionalizado, cientificizado, tecnicizado. Chega de chorar sobre o desencanto do mundo!" (Latour, 1994, p. 143).

$\mathrm{Na}$ prática, o ideal racionalista, cientificista e tecnicista da modernidade não pôde nunca se completar. Como nas sociedades primitivas, a vida econômica na modernidade capitalista também está imersa na cultura. Considerar onças, bois, cachorros, águias, serpentes, montanhas e rios como seres dotados de alma é um comportamento tão cultural quanto considerá-los meros objetos a disposição dos seres humanos, redutíveis à satisfação de necessidades calóricas, sensoriais ou pecuniárias.

A sociedade moderna, como todas as demais, também depende de crenças costumeiras, religiosas, místicas e espirituais para a sua legitimação. Nossa sociedade não é baseada somente no cálculo utilitarista, nas diversas formas de racionalidade ou nos interesses econômicos. $\mathrm{O}$ comportamento humano na modernidade capitalista é também um comportamento cultural. ${ }^{11}$

Ninguém jamais ouviu falar de um coletivo que não mobilizaria, em sua composição, o céu, a terra, as corpos, os bens, o direito, os deuses, as almas, os ancestrais, as forças, os animais, as crenças, os seres fictícios... Esta é a antiga matriz antropológica, que jamais deixamos de lado (Latour, 1994, p. 132).

Sahlins (1976) descreve inúmeros exemplos que indicam como o comportamento econômico está inserido na esfera da cultura. Os exemplos do mundo do consumo são os mais expressivos e o fazem concluir que o consumo em nada se reduz à escolha individual em termos de custos e benefícios. A aquisição de automóveis, as escolhas de materiais, cores e formas do mundo da moda, a separação e hierarquização dos cortes de carne, a definição de quais animais são comestíveis e a delimitação de

11 "Todas as naturezas-culturas são similares por construírem ao mesmo tempo os seres humanos, divinos e não humanos. Nenhuma delas vive em um mundo de signos ou de símbolos arbitrariamente impostos a uma natureza exterior que apenas nós conhecemos. Nenhuma delas, e sobretudo não a nossa, vive em um mundo de coisas" (Latour, 1994, p. 132). 
quais animais podem ser bichos de estimação são amostras de como o comportamento dos consumidores não se baseia apenas em fatores racionais, objetivos ou quantificáveis. ${ }^{12}$

Sahlins (1976, p. 8-10; 200) procura inserir a sociedade burguesa no âmbito da ordem simbólica. Em outras palavras, defende que é necessária "a incursão na economia capitalista como sistema cultural". De acordo com o autor, a cultura supera dualismos presentes nas ciências humanas, tais como entre "espírito e matéria" ou entre "idealismo e materialismo". A cultura possibilita a superação dessas dicotomias porque ela é a "mediação entre 'sujeito/objeto'”. Em outras palavras, as culturas "são ordens de significado de pessoas e coisas" (Sahlins, 1976, p. 10).

A concepção de Sahlins de que a economia capitalista é um sistema cultural possibilita a introdução do terceiro tipo de crítica dirigido à mentalidade econômica: o questionamento de que o utilitarismo, o calculismo e outras formas de racionalidade econômica sejam formas neutras, puras, sejam as racionalidades por excelência e, por isso, estariam fora do âmbito da cultura.

Lévi-Strauss, diferenciando as ciências humanas das sociais, argumenta que as últimas tendem a atribuir à sociedade do observador um valor transcendental. O pensador francês aponta a economia e o direito como duas das ciências sociais por excelência. Essas ciências consideram que o universo material e simbólico na qual estão inseridas é "supercultural", está fora e acima do âmbito da cultura.

\footnotetext{
Proibindo-se qualquer complacência, mesmo de ordem epistemológica, para com seu objeto, as ciências humanas adotam o ponto de vista da imanência; enquanto as ciências sociais, privilegiando a sociedade do observador, atribuem a esta um valor transcendental. Isto é muito claro no caso dos economistas, que não hesitam em proclamar, para justificar a estreiteza de sua visão, que a racionalidade econômica é um estado privilegiado da natureza humana e que surgiu num certo momento da história e num certo ponto do mundo. E não é menos claro no caso dos juristas, que tratam um sistema artificial como se fosse real e que, para descrevê-lo, partem do postulado que ele não poderia englobar contradições. Por isto foram comparados freqüentemente a teólogos. É indiscutivel que a transcendência à qual se referem as ciências sociais, implícita ou explicitamente, não é de ordem sobrenatural. Mas é, pode-se dizer, "supercultural": isola uma cultura particular, coloca-a acima das outras, trata-a como um universo separado que contém sua própria legitimação (Lévi-Strauss, 1952, p. 312-313).
}

12 Veblen (1899), como visto, foi pioneiro na análise do "consumo conspícuo", o consumo como forma de ostentar, definir status social por meio da comparação competitiva entre níveis de consumo e riqueza. 
O pensamento denunciado por Lévi-Strauss acima é predominante no Ocidente moderno e está fortemente enraizado no pensamento econômi$\mathrm{co}$, que considera a racionalidade utilitarista e calculista superior às demais racionalidades. A ideia de que a sociedade ocidental moderna é superior às demais é usada como justificativa para todo tipo de dominação: sobre outros povos e sobre todos os outros animais do planeta.

Nós, só nós, os europeus, somos os humanos completos e acabados, ou melhor,
grandiosamente inacabados, os exploradores destemidos de mundos desconhe-
cidos (plus ultra!), os acumuladores de mundos, os milionários em mundo, os
"configuradores de mundos". Como se vê, a metafisica ocidental é a fons et
origo de toda a espécie de colonialismo - interno (intraespecífico), externo (inte-
respecífico), e se pudesse, eterno (intemporal) (Viveiros de Castro, 2018, p. 27).

De acordo com Latour (1994, 2004), a modernidade é definida a partir da centralidade do antropocentrismo e das consequências que ele provoca. Juntamente com o humano, se estabelece o não humano, o mundo das coisas, da matéria, completamente inferiorizado e subjugado pela modernidade capitalista, que tem como ideal separar completamente a sociedade da natureza. A sociedade ocidental procura estabelecer e acentuar as "grandes divisões" entre "modernos e antigos", entre "natureza e sociedade", entre "ciência e cultura", entre humanos e coisas. A modernidade capitalista também procura, depois de séculos de guerras religiosas, guardar a religiosidade apenas no âmbito privado.

A modernidade é muitas vezes definida através do humanismo, seja para saudar
o nascimento do homem, seja para anunciar sua morte. Mas esse próprio hábito
é moderno, uma vez que este continua sendo assimétrico. Esquece o nascimento
conjunto da "não humanidade" das coisas, dos objetos ou das bestas, e o nasci-
mento, tão estranho quanto o primeiro, de um Deus suprimido, fora do jogo. A
modernidade decorre da criação conjunta dos três, e depois da recuperação deste
nascimento conjunto e do tratamento separado das três comunidades enquanto
que, embaixo, os híbridos continuavam a multiplicar-se como uma consequência
direta deste tratamento em separado. É esta dupla separação que precisamos
reconstituir, entre o que está acima e o que está abaixo, de um lado, entre os
humanos e os não humanos, de outro (Latour, 1994, p. 19).

Entretanto, como visto, "jamais fomos modernos". A modernidade capitalista também é baseada em crenças, costumes, valores, fé. Além disso, a nossa sociedade também é completamente inserida e inseparável do mundo natural. De acordo com Latour (1994; 2004), é necessário reconstruir o pensamento social sem reduzir a sociedade à natureza, à política ou ao discurso. Para isso, seria fundamental considerar a importância dos "híbridos" (ou da "associação de humanos e não humanos"): a maior parte da realidade contemporânea seria composta por elementos que misturam itens da 
natureza, interesses político-sociais e é compreendida por intermédio da linguagem. Vivemos no que Latour (1994; 2004) chama de "naturezas-culturas", ou em um "mundo comum" formado pela "associação de humanos e não humanos". Para compreender o mundo comum é fundamental substituir o trabalho de separação e purificação (típico das ciências exatas e sociais) pelo trabalho de mediação.

Mesmo autores do porte de Marx, ${ }^{13}$ Veblen e Furtado tendem a separar, de um lado, a natureza, entendida enquanto "força material", "ambiente material", fonte de "recursos não renováveis" ou "mundo físico" e, de outro lado, a sociedade, caracterizada pela reprodução e pela transformação de "relações sociais", "hábitos" ou "instituições". Tal separação é uma característica da modernidade, não está presente em todas as sociedades. ${ }^{14}$ Rejeitar a separação radical entre sociedade e natureza pode ajudar na construção de uma sociedade menos destrutiva para o planeta, como Marx, Veblen e Furtado desejaram.

De acordo com Descola (2016, p. 26), a sociedade em que vivemos, que nos parece eterna, é "apenas uma entre milhares" de maneiras diversas de se "viver a condição humana". Comparar a modernidade capitalista com as culturas tradicionais possibilita ao observador um distanciamento crítico em relação à nossa própria cultura, "nos fornece uma maneira de tomar distância do presente para melhor tentar enfrentar o futuro" (Descola, 2016, p. 26).

De modo algum analisar o pensamento moderno de forma crítica implica negar as contribuições científicas, sociais e políticas da modernidade e adotar algum tipo de pós-modernismo relativista e niilista. Implica entender melhor a sociedade-natureza em que habitamos e estabelecer elementos para uma compreensão mais profunda da atuação humana neste planeta. Aprofundar e sofisticar o humanismo, em vez de defender a reificação de tudo e de todos.

13 Por exemplo, tratando do trabalho, Marx argumenta que o "processo de trabalho, como expusemos em seus momentos simples e abstratos, é atividade orientada a um fim - a produção de valores de uso -, apropriação do elemento natural para a satisfação de necessidades humanas, condição universal do metabolismo entre homem e natureza, perpétua condição natural da vida humana e, por conseguinte, independente de qualquer forma particular dessa vida, ou melhor, comum a todas as suas formas sociais" (Marx, 1867, p. 261).

14 "Para as centenas de tribos amazônicas, que falam línguas diferentes, os não humanos também são pessoas que participam da vida social, pessoas com quem podemos estabelecer relações de aliança ou, ao contrário, relações de hostilidade e de competição. Essa forma de ver o que chamamos natureza como algo idêntico à sociedade dos homens também não é uma característica exclusiva da Amazônia" (Descola, 2016, p. 14). 


\section{Considerações finais}

Este artigo analisou criticamente as relações entre o pensamento econômico e a cultura. Para tanto, foi apresentado como o conceito de cultura é tratado pelas abordagens econômicas dominantes, desde Adam Smith até a economia neoclássica da cultura. De acordo com essas abordagens, a racionalidade humana é predominantemente calculista e utilitarista. A esfera cultural é externa ao âmbito econômico e só o influencia indiretamente.

$\mathrm{Na}$ segunda parte do artigo, foram apresentados elementos para o entendimento da cultura em três autores fundamentais da heterodoxia econômica: Marx, Veblen e Furtado. Esses autores criticam profundamente o pensamento econômico dominante e constroem conceitos que historicizam, criticam e relativizam as sociedades capitalistas. Entretanto, também adotam preceitos da modernidade capitalista, tais como a separação entre sociedade e natureza e a explicação das culturas a partir de fatores materiais ou ligados a interesses materiais.

Por fim, na terceira parte do artigo, foram apresentadas críticas tanto sobre a maneira como o pensamento econômico retrata as culturas não ocidentais quanto sobre a predominância da racionalidade capitalista na sociedade moderna, bem como sobre a impressão de que a racionalidade econômica está fora da esfera da cultura. Um entendimento mais aprofundado da sociedade capitalista e uma atuação mais informada das ciências sociais e humanas na realidade implicam uma análise mais profunda dos pressupostos culturais da modernidade sem, obviamente, rejeitá-la completamente.

\section{Referências}

BECKER, G. The economics of discrimination. Chicago: University of Chicago Press, 1957.

BECKER, G; MURPHY, K. A theory of rational addiction. The Journal of Political Economy, v. 96, n. 4, 1988.

BENTHAM, J. Uma introdução aos princípios da moral e da legislação. São Paulo: Abril Cultural, 1984 (1780).

DEQUECH, D. Neoclassical, mainstream, orthodox and heterodox economics. Journal of Post Keynesian Economics, v. 30, n. 2, 2007.

DESCOLA, P. Outras naturezas, outras culturas. São Paulo: Editora 34, 2016.

FERNÁNDEZ, R. Culture and economics. In: DURLAUF, S; BLUME, L. (Ed.). The New Palgrave Dictionary of Economics. $2^{\text {nd }}$ Ed. Manchester: Palgrave Macmillan, 2008. 
FURTADO, C. O mito do desenvolvimento econômico. Rio de Janeiro: Paz e Terra, 1996 (1974).

FURTADO, C. O capitalismo global. Rio de Janeiro: Paz e Terra, 1998.

FURTADO, C. Criatividade e dependência na civilização industrial. São Paulo: Companhia das Letras, 2008 (1978).

GRIEF, A. Cultural beliefs and the organization of society: a historical and theoretical reflection on collectivist and individualist societies. Journal of Political Economy, v. 102, n. 5, 1994.

GUISO, L; SAPIENZA, P; ZINGALES, L. Does culture affect economic outcomes? Journal of Economic Perspectives, v. 20, n. 2, 2006.

JEVONS, W. S. Teoria da economia política. São Paulo: Abril Cultural, 1983 (1871).

KOPENAWA, D; ALBERT, B. A queda do céu: palavras de um xamã yanomami. São Paulo: Companhia das Letras, 2015.

LATOUR, B. Jamais fomos modernos: ensaio de antropologia simétrica. Rio de Janeiro: Ed. 34, 1994.

LATOUR, B. Politicas da natureza: como fazer ciência na democracia. Bauru: EDUSC, 2004.

LEE, F. History of heterodox economicsestrutural: challenging the mainstream in the twentieth century. Nova York: Routledge, 2009.

LEVÍ-STRAUSS, C. Antropologia estrutural. Rio de Janeiro: Tempo Brasileiro, 1993 (1952). v. II.

MALINOWSKI, B. Os argonautas do Pacífico ocidental. São Paulo, Editora Abril, 1978 (1922).

MARX, K. Contribuição à crítica da economia política. São Paulo: Expressão Popular, 2008 (1859).

MARX, K. Grundrisse. São Paulo: Boitempo; Rio de Janeiro: Editora UFRJ, 2011 (1857-1858).

MARX, K. O capital: crítica da economia política. São Paulo: Boitempo, 2013 (1867). v. 1.

MARX, K; ENGELS, F. Manifesto do partido comunista. São Paulo: Boitempo, 1998 (1848).

MAUSS, M. Ensaio sobre a dádiva: forma e razão da troca em sociedades arcaicas. In: Sociologia e antropologia. São Paulo: Cosac Naify, 2003 (1922).

MENGER C. Princípios de economia política. São Paulo: Abril Cultural, 1983 (1871).

MIROWSKI, P. More heat than light: economics as social physics, physics as nature's economics. Cambridge: Cambridge University Press, 1989.

MIROWSKI, P. Machine dreams: economics becomes a cyborg science. Nova York: Cambridge University Press, 2002.

POLANYI, K. A grande transformação. As origens da nossa época. Rio de Janeiro: Campus, 2000 (1944).

ROBBINS, L. An essay on the nature and significance of economic science. Londres: Macmillan, 1932.

SAHLINS, M. Cultura e razão prática. Rio de Janeiro: Zahar, 2003 (1976).

SMITH, A. A riqueza das nações: investigação sobre sua natureza e suas causas. São Paulo: Nova Cultural, 1996 (1776).

VEBLEN, T. Why is economics not an evolutionary science. The Quarterly Journal of Economics, v. 12, 1898. 
VEBLEN, T. A teoria da classe ociosa. São Paulo: Abril Cultural, 1982 (1899).

VEBLEN, T. The theory of the business enterprise. Nova York: Charles Scribners, 1904.

VEBLEN, T. The socialist economics of Karl Marx and his followers I. The Quarterly Journal of Economics, v. XX, 1906.

VEBLEN, T. The socialist economics of Karl Marx and his followers II. The Quarterly Journal of Economics, v. XXI, 1907.

VEBLEN, T. The instinct of workmanship and the state of the industrial arts. Blackmask Online, 2003 (1914).

VIVEIROS DE CASTRO, E. Metafísicas canibais: elementos para uma antropologia pós-estrutural. São Paulo: Ubu Editora, N-I Edições, 2018.

\section{Sobre o autor}

Marcelo Soares Bandeira de Mello Filho - marcelosbmf@gmail.com

Universidade Federal de São João del-Rei, São João del-Rei, Minas Gerais, Brasil.

ORCID: https://orcid.org/0000-0001-6322-3496.

\section{Sobre o artigo}

Recebido em 01 de dezembro de 2019. Aprovado em 24 de fevereiro de 2020. 